\title{
The Variant p.(Arg183Trp) in SPTLC2 Causes Late-Onset Hereditary Sensory Neuropathy
}

\section{Suriyanarayanan, Saranya}

2016-03

Suriyanarayanan , S, Auranen , M , Toppila , J , Paetau , A , Shcherbii , M , Palin , E , Wei , Y, Lohioja , T , Schlotter-Weigel , B , Schoen , U , Abicht , A, Rautenstrauss , B , Tyynismaa , H , Walter , M C , Hornemann , T \& Ylikallio , E 2016 , ' The Variant p.(Arg183Trp) in SPTLC2 Causes Late-Onset Hereditary Sensory Neuropathy ' , NeuroMolecular Medicine , vol. 18 , no. 1 , pp. 81-90 . https://doi.org/10.1007/s12017-015-8379-1

http://hdl.handle.net/10138/223887

https://doi.org/10.1007/s12017-015-8379-1

publishedVersion

Downloaded from Helda, University of Helsinki institutional repository.

This is an electronic reprint of the original article.

This reprint may differ from the original in pagination and typographic detail.

Please cite the original version. 


\title{
The Variant p.(Arg183Trp) in SPTLC2 Causes Late-Onset Hereditary Sensory Neuropathy
}

\author{
Saranya Suriyanarayanan ${ }^{1,2} \cdot$ Mari Auranen ${ }^{3,4} \cdot$ Jussi Toppila $^{5} \cdot$ Anders Paetau $^{6} \cdot$ \\ Maria Shcherbii $^{3} \cdot$ Eino Palin $^{3} \cdot$ Yu Wei ${ }^{1}$ Tarja Lohioja ${ }^{7}$ - Beate Schlotter-Weigel ${ }^{8}$. \\ Ulrike Schön9 • Angela Abicht ${ }^{9}$ - Bernd Rautenstrauss ${ }^{9} \cdot$ Henna Tyynismaa $^{3}$. \\ Maggie C. Walter ${ }^{8} \cdot$ Thorsten Hornemann $^{1,2} \cdot$ Emil Ylikallio $^{3}$
}

Received: 13 August 2015/Accepted: 5 November 2015/Published online: 16 November 2015

(C) Springer Science+Business Media New York 2015

\begin{abstract}
Hereditary sensory and autonomic neuropathy 1 (HSAN1) is an autosomal dominant disorder that can be caused by variants in SPTLC1 or SPTLC2, encoding subunits of serine palmitoyl-CoA transferase. Disease variants alter the enzyme's substrate specificity and lead to accumulation of neurotoxic 1-deoxysphingolipids. We describe two families with autosomal dominant HSAN1C caused by a new variant in $S P T L C 2$, c.547C $>$ T, p.(Arg183Trp). The variant changed a conserved amino acid and was not found in public variant databases. All patients had a relatively mild
\end{abstract}

Electronic supplementary material The online version of this article (doi:10.1007/s12017-015-8379-1) contains supplementary material, which is available to authorized users.

Emil Ylikallio

emil.ylikallio@helsinki.fi

1 Institute for Clinical Chemistry, University Hospital Zurich, University of Zurich, Zurich, Switzerland

2 Competence Center for Personalized Medicine (CC-PM), Zurich, Switzerland

3 Research Programs Unit, Molecular Neurology, Biomedicum Helsinki, University of Helsinki, Haartmaninkatu 8, 00290 Helsinki, Finland

4 Clinical Neurosciences, Neurology, University of Helsinki and Helsinki University Hospital, Helsinki, Finland

5 Department of Clinical Neurophysiology, Medical Imaging Center, Helsinki University Central Hospital, Helsinki, Finland

6 Department of Pathology, HUSLAB, University of Helsinki, Helsinki, Finland

7 Neurocenter, Kuopio University Hospital, Kuopio, Finland

8 Friedrich-Baur-Institute, Department of Neurology, LudwigMaximilians-University of Munich, Munich, Germany

9 Medical Genetics Centre, Munich, Germany progressive distal sensory impairment, with onset after age 50. Small fibers were affected early, leading to abnormalities on quantitative sensory testing. Sural biopsy revealed a severe chronic axonal neuropathy with subtotal loss of myelinated axons, relatively preserved number of nonmyelinated fibers and no signs for regeneration. Skin biopsy with PGP9.5 labeling showed lack of intraepidermal nerve endings early in the disease. Motor manifestations developed later in the disease course, but there was no evidence of autonomic involvement. Patients had elevated serum 1-deoxysphingolipids, and the variant protein produced elevated amounts of 1-deoxysphingolipids in vitro, which proved the pathogenicity of the variant. Our results expand the genetic spectrum of HSAN1C and provide further detail about the clinical characteristics. Sequencing of SPTLC2 should be considered in all patients presenting with mild lateonset sensory-predominant small or large fiber neuropathy.

Keywords Neuropathy $\cdot$ Hereditary sensory autonomic neuropathy $\cdot$ Serine palmitoyl-CoA transferase .

Sphingolipid

\begin{tabular}{ll}
\multicolumn{2}{l}{ Abbreviations } \\
1-deoxySL & 1-Deoxysphingolipid \\
DML & Distal motor latency \\
ENMG & Electroneuromyography \\
HbA $_{1 C}$ & Glycated hemoglobin \\
HSAN & Hereditary sensory and autonomic \\
& neuropathy \\
NCV & Nerve conduction velocity \\
QST & Quantitative sensory testing \\
SA & Sphinganine \\
SISu & Sequencing Initiative Suomi \\
SO & Sphingosine \\
SPT & Serine palmitoyl-CoA transferase
\end{tabular}




\section{Introduction}

Hereditary sensory and autonomic neuropathy (HSAN) is a diverse group of diseases of the peripheral nervous system. Autosomal dominant HSAN1 and autosomal recessive HSAN2 generally cause progressive distal impairment of all sensory modalities with minimal autonomic involvement, whereas autonomic symptoms predominate in HSAN3 (Houlden et al. 2004). HSAN1 is associated with variants in six genes: SPTLC1 (Bejaoui et al. 2001; Dawkins et al. 2001), SPTLC2 (Rotthier et al. 2010), ATL1 (Guelly et al. 2011), DNMT1 (Klein et al. 2011), $R A B 7$ (Verhoeven et al. 2003), and ATL3 (Kornak et al. 2014). SPTLC1 and SPTLC2 encode subunits of the enzyme serine palmitoyl-CoA transferase (SPT). SPT is located in the endoplasmic reticulum, and it catalyzes the rate-limiting step in the de novo biosynthesis of sphingolipids, i.e., condensation of L-serine with palmitoyl-CoA (Hanada 2003). Sphingolipids are vital components of cell membranes that serve multiple structural and signaling functions. The pathophysiology of SPTrelated HSAN1 (termed HSAN1A for SPTLC1 variants and HSAN1C for $S P T L C 2$ variants) is considered to result from the accumulation of aberrant sphingolipid species (Penno et al. 2010). Disease-causing variants in SPTLCl shift the enzyme's substrate specificity such that L-alanine or glycine is incorporated in place of $\mathrm{L}$-serine. This results in the production of 1-deoxysphingolipids lacking the C1-hydroxyl group (1deoxySLs). The 1-deoxySLs have neurotoxic properties and are thought to be responsible for the development of neuropathy (Penno et al. 2010).

Disease-associated variants in SPTLC2 have been found to similarly impair the enzyme's amino acid selectivity and induce the synthesis of 1-deoxySL, causing its accumulation in HSAN1C patients' serum (Rotthier et al. 2010; Murphy et al. 2013; Ernst et al. 2015). Moderate accumulation of 1-deoxySL also occurs in metabolic syndrome and type 2 diabetes (Othman et al. 2012) and might be involved in the pathology of the diabetic sensory neuropathy (Othman et al. 2015a, b).

Increased availability of L-serine has been suggested as a means to counter the promiscuous use of the non-canonical amino acids by mutant SPT (Garofalo et al. 2011). The proper identification and clinical characterization of HSAN1A and C patients is therefore of great importance as they would qualify for such a specific treatment in the near future.

\section{Patients and Methods}

\section{Patients}

The index patient of the Finnish family (family F) was seen at the Helsinki University Hospital and underwent electroneuromyography (ENMG), quantitative sensory testing (QST), skin biopsy, autonomic testing, and muscle MRI using standard techniques. Skin biopsy small fiber density was analyzed by PGP9.5 labeling as described (Koskinen et al. 2005). Total DNA was extracted from blood. All participants gave written informed consent, and the study was approved by the Ethics Committee, Department of Medicine, Hospital District of Helsinki and Uusimaa (dnro 399/E9/07).

The two German patients (family G)—father and sonwere examined at the Friedrich-Baur-Institute, LudwigMaximilians-University of Munich, Germany. Within the routine diagnostic work-up, clinical testing and ENMG were performed in both patients, while sural nerve biopsy was only done in the father. DNA was extracted from blood for genetic testing, and both patients gave written informed consent.

\section{DNA Sequencing}

In family $\mathrm{F}$, the index patient's sample was subjected to targeted gene panel sequencing using the HaloPlex Target Enrichment Kit (Agilent Technologies, Santa Clara, CA, USA) and a MiSeq sequencer (Illumina, San Diego, CA, USA), as previously described (Ylikallio et al. 2014). Variants were annotated using Annovar (Wang et al. 2010). Findings were confirmed by Sanger sequencing of SPTLC2 exon 4 . In the index patient of family $\mathrm{G}$, all coding exons of SPTLC1, SPTLC2, MFN2, BSCL2, and GARS were analyzed by Sanger sequencing. Primer sequences are available on request.

Variant pathogenicity was predicted by PolyPhen-2 version 2.2.2 (http://genetics.bwh.harvard.edu/pph2/) (Adzhubei et al. 2010) and Combined Annotation Dependent Depletion version 1.2 (CADD, http://cadd.gs.washington. edu/) (Kircher et al. 2014). The Sequencing Initiative Suomi (SISu) database (Lim et al. 2014), which contains sequencing data from $>3000$ individuals, was used to estimate variants' prevalence in the Finnish population.

\section{Haplotype Analysis}

Disease-associated haplotypes were determined by analyzing four STS markers surrounding the SPTLC2 gene (AFM158XB4, D14S59, D14S109E, and AFM214XF8). PCR amplification was performed with forward primers labeled with 5'-6FAM dye. Fragments were run on an ABI3730XL DNA analyzer and analyzed with GeneMapper Software 5 (Applied Biosystems).

\section{Lipid Analysis}

$500 \mu \mathrm{l}$ of MetOH (Honeywell, Germany) including 200 pmol of deuterated internal standards (d7-sphinganine 
and d7-sphingosine, Avanti Polar Lipids) were added to the resuspended cell pellets (2-5 mio cells in $100 \mu \mathrm{l}$ PBS) or $100 \mu \mathrm{l}$ of serum. Serum samples were collected from affected and unaffected family members. Lipids were extracted at $37^{\circ} \mathrm{C}$ for $1 \mathrm{~h}$ with constant agitation. Precipitated protein was pelleted by centrifugation $(16000 \mathrm{~g}$, $5 \mathrm{~min}$ ), and $500 \mu \mathrm{l}$ was transferred to a new tube. Lipids were hydrolyzed by adding $75 \mu \mathrm{l}$ of HCL (32\%) and incubated at $65^{\circ} \mathrm{C}$ for $16 \mathrm{~h}$. $100 \mu \mathrm{l} \mathrm{KOH} \mathrm{(10} \mathrm{M)} \mathrm{was}$ added to neutralize the HCL, followed by the addition of $125 \mu \mathrm{l}$ of chloroform, $100 \mu \mathrm{l}$ of ammonium hydroxide $(2 \mathrm{~N})$, and $500 \mu \mathrm{l}$ of alkaline water for the extraction of free sphingoid bases. The sphingoid bases were separated on C18 column (Uptispere $120 \AA$, $5 \mu \mathrm{m}, 125 \times 2 \mathrm{~mm}$, Interchim, France) and analyzed on a TSQ Quantum Ultra MS analyzer (Thermo Scientific).

\section{SPT Activity Assay}

HEK293 cells were stably transfected with the SPTLC2 p.(Arg183Trp) mutant or the empty vector (pcDNA3.1, Invitrogen). Cells were cultured in DMEM (SigmaAldrich), including $400 \mu \mathrm{g} / \mathrm{ml}$ of Geneticin (Gibco, Invitrogen), $10 \%$ fetal bovine serum (Gibco, Life Technologies), and penicillin/streptomycin (100 U/ml, SigmaAldrich). After 2 days, the medium was exchanged, and the cells were pre-incubated with L-serine, L-alanine-deficient DMEM (Genaxxon). After $2 \mathrm{~h}$, isotope-labeled (2,3,3-d3, $\left.{ }^{15} \mathrm{~N}\right)$ L-serine $(1 \mathrm{mM}$ and $10 \mathrm{mM})$ and $(2,3,3,3) \mathrm{d} 4$-L-alanine (2 and $10 \mathrm{mM}$ ) was added. The SPT inhibitor myriocin $(2.5 \mu \mathrm{M})$ was used as a negative control. After $24 \mathrm{~h}$, the cells were harvested, counted (Z2 Coulter Counter, Beckman Coulter, CA), pelleted $\left(800 \times g\right.$ at $\left.4{ }^{\circ} \mathrm{C}, 5 \mathrm{~min}\right)$, and analyzed as described below.

\section{Results}

\section{Clinical Characteristics}

Clinical and neurophysiologic features of all mutationpositive individuals are presented in Table 1. The index patient in the Finnish family (Fig. 1a, family F: 323) had distal sensory symptoms in lower limbs, later progressing to muscle weakness and involvement of upper limbs. At age 67 , the patient was obese (height $165 \mathrm{~cm}$, weight $98 \mathrm{~kg}$, BMI 36), and edema was noted in both legs. She was ambulant without external aids and able to walk on toes and heels with difficulty. In upper limbs, distal muscle strengths were normal. Upper limb sensory impairment was restricted to fingertips, and sensation for light touch, pinprick, and vibration were otherwise intact. Deep tendon reflexes were absent in lower limbs and weakly present in upper limbs. Pinprick sensation was weakened, and vibration sense was absent distally in legs. Thigh flexion strengths were decreased 4/5, knee flexion-extension strengths were normal, and ankle flexion-extension strengths were decreased $4 / 5$. No skin ulcerations were noted.

ENMG showed recordable but decreased sensory amplitudes in distal legs, suggesting at most a mild sensory axonal neuropathy. QST revealed decreased sensation for vibration and cold distally in upper and lower limbs. Skin biopsy with PGP9.5 staining of small nerve fibers showed no intraepidermal nerve fibers in $6 \mathrm{~mm}$ of epidermis (Fig. 2a), which contrasted with a biopsy from a neurologically intact control (Fig. 2b). The density of epidermal nerve fibers in the patient was thus $0 / \mathrm{mm}$ of epidermis, indicative of small fiber neuropathy $(<2$ fibers $/ \mathrm{mm}$ is considered to indicate small fiber neuropathy). Autonomic testing revealed no evidence for abnormal blood pressure or pulse responses upon rising or in response to paced or deep breathing or Valsalva testing. Lower limb muscle MRI at age 65 gave normal, symmetric results with no fatty degeneration.

The index patient's two siblings had similar symptoms, and ENMG performed on her sister revealed comparable findings (Table 1). Her 50-year-old niece, individual 514, had only minor symptoms and normal ENMG (Table 1). However, QST showed elevation of sensory threshold to cold in lower limbs, indicative of mild impairment of A-delta small fibers. A skin biopsy showed two intraepidermal nerve fibers in $3 \mathrm{~mm}$ of epidermis (2/3 nerve fibers per $\mathrm{mm}$ ), indicative of small fiber neuropathy.

The index patient in the German family (family G, III:1) noticed first symptoms at age 50 with mild hypoesthesia of the feet and later dysesthesia of the lower legs up to his knees; during the course of the disease, hands became also affected. Tendon reflexes were normal; muscle weakness was noted in toe extensors $3 / 5$ and toe flexors $4 / 5$. Walking on tiptoes and heels was not impaired, and only mild sensory ataxia was noticed.

Neurophysiologic testing at age 62 revealed a sensorimotor axonal neuropathy; nerve conduction velocity (NCV) of the right median nerve was $38 \mathrm{~m} / \mathrm{s}$, distal motor latency (DML) was normal, amplitudes were reduced; the right ulnar nerve showed normal NCV and DML, but also reduced amplitudes; motor nerves of the lower extremities (peroneal and tibial nerves) were not obtainable. No sensory NCVs could be obtained. Electromyography displayed some neurogenic changes in distal muscles of the lower limbs.

Cerebrospinal fluid examination showed normal results, and biopsy of the sural nerve displayed a severe chronic axonal neuropathy with subtotal loss of myelinated axons and no signs for regeneration (Fig. 2c). The number of non- 
Table 1 Clinical characteristics of individuals with SPTLC2 p.Arg183Trp variant

\begin{tabular}{|c|c|c|c|c|c|c|c|}
\hline Patient & Family & Sex & $\mathrm{AAO}$ & Initial symptoms & Later symptoms & ENMG & Other \\
\hline 323 & $\mathrm{~F}$ & $\mathrm{~F}$ & 54 & $\begin{array}{l}\text { Distal LL } \\
\text { numbness }\end{array}$ & $\begin{array}{l}\text { Age 67: distal UL numbness, } \\
\text { burning and clumsiness; LL } \\
\text { weakness }\end{array}$ & $\begin{array}{l}\text { Mild-to-moderate } \\
\text { axonal sensorimotor } \\
\text { neuropathy }\end{array}$ & $\begin{array}{l}\text { Skin biopsy: SFN } \\
\text { Hypertension, receives } \\
\text { vitamin B12 substitution, } \\
\text { no diabetes }\end{array}$ \\
\hline 481 & $\mathrm{~F}$ & $\mathrm{~F}$ & $\sim 50$ & $\begin{array}{l}\text { LL hypoesthesia } \\
\text { and pains }\end{array}$ & $\begin{array}{l}\text { UL and LL numbness and } \\
\text { weakness }\end{array}$ & $\begin{array}{l}\text { Mild axonal } \\
\text { sensorimotor } \\
\text { neuropathy }\end{array}$ & $\begin{array}{l}\text { Type } 2 \text { diabetes treated by } \\
\text { oral medication }\end{array}$ \\
\hline 463 & $\mathrm{~F}$ & M & $\sim 60$ & $\begin{array}{l}\text { Distal UL } \\
\text { numbness and } \\
\text { clumsiness }\end{array}$ & $\begin{array}{l}\text { Age } 72 \text { : chronic foot infection } \\
\text { leading to amputation }\end{array}$ & ND & $\begin{array}{l}\text { Intervertebral disk infection } \\
\text { No diabetes }\end{array}$ \\
\hline 514 & $\mathrm{~F}$ & $\mathrm{~F}$ & 50 & $\begin{array}{l}\text { Numbness and } \\
\text { tingling in right } \\
\text { hand }\end{array}$ & - & Normal at age 50 & $\begin{array}{l}\text { Skin biopsy: SFN } \\
\text { No diabetes }\end{array}$ \\
\hline III: 1 & G & M & 50 & LL hypoesthesia & $\begin{array}{l}\text { Gait ataxia, LL weakness, toe } \\
\text { amputation }\end{array}$ & $\begin{array}{l}\text { Sensorimotor axonal } \\
\text { neuropathy }\end{array}$ & $\begin{array}{l}\text { Sural biopsy: severe chronic } \\
\text { axonal neuropathy } \\
\text { Subclinical diabetes } \\
\text { suspected }\end{array}$ \\
\hline IV:1 & G & M & - & $\begin{array}{l}\text { No symptoms at } \\
\text { age } 26\end{array}$ & - & Normal at age 26 & - \\
\hline
\end{tabular}

$A A O$ age at onset, $L L$ lower limbs, $E N M G$ electroneuromyography, $N D$ not done, $U L$ upper limb, $S F N$ small fiber neuropathy

myelinated fibers was relatively preserved in all nerve fascicles (Fig. 2d). Five years later, at age 67, the patient suffered from gait ataxia, walking on heels was no longer possible and walking on tiptoes strenuous. Achilles tendon reflexes were absent. Amputation of the second toe of the left foot was noticed. Hypoesthesia was evident in a glove and stocking pattern in all limbs increasing distally in form of short socks; vibration sense was absent in both feet and decreased with $3 / 8$ on knee level. Dysesthesia in hands and legs was reported. Additionally, a subclinical diabetes type II was suspected at age 67 on the basis of an elevated $\mathrm{HbA}_{1 \mathrm{C}}$. On the last clinical visit, the $\mathrm{HbA}_{1 \mathrm{C}}$ was normal.

The son of the index patient (IV:1) was examined at age 26 and the daughter (IV:2) at age 23; both did not show any signs of a sensory neuropathy in clinical or electrophysiological analysis.

\section{Genetic Findings}

Targeted panel sequencing of known neuropathy-related genes was carried out to identify potential disease-causing variants in the index patient of family $F$. The analysis revealed a single novel variant, c.547C $>\mathrm{T}$ (p. $(\operatorname{Arg} 183 \operatorname{Trp}))$ in SPTLC2 (NM_004863.3). Other identified variants that alter amino acid sequence or splice sites are listed in supplementary Table 1 . The SPTLC2 variant was confirmed by Sanger sequencing (Fig. 1b) and segregated with the disease phenotype within the family. The affected amino acid, Arg183, is conserved in mammals (Fig. 1c). The variant was rated "possibly damaging" by PolyPhen 2 and received a scaled C-score of 25.3 in CADD.
In family $\mathrm{G}$, a candidate gene sequencing approach revealed the same c.547C $>\mathrm{T}$ (p.(Arg183Trp)) mutation in SPTLC2, after exclusion of variants in SPTLC1, MFN2, $B S C L 2$, and GARS. The same mutation was also found in the half-brother of the patient (III:3), also suffering from a sensory neuropathy, and in the patient's son (IV:1), who did not yet show any symptoms (age 26). The daughter (IV:2) did not harbor the mutation. The father of the index patient (II:2), the father's sister (II:4), and her daughter (III:5) were also reported to suffer from sensory loss in hands and legs, but were not available for genetic examination (Fig. 1a).

Analysis of STS markers surrounding SPTLC2 showed that the disease-associated haplotypes were not shared by families $F$ and $G$ (Table 2). This suggested that the variant has arisen on separate occasions in the two families.

\section{SPT Activity}

SPT activity was analyzed in HEK293 cells transfected with SPTLC2 p.(Arg183Trp), wild-type SPTLC2 or the empty vector (pcDNA3.1). 24-h after the addition of isotope-labeled serine $(1 \mathrm{mM})$ and alanine $(2 \mathrm{mM})$, the incorporation of the label into de novo formed sphingoid bases was quantified by LC-MS. We observed no significant difference in the canonical SPT activity (SA + SO) between SPTLC2 p.(Arg183Trp)- and SPTLC2wt-expressing cells. In contrast, we observed a significantly increased 1-deoxySLs (1-deoxySA and 1-deoxySO) formation for the SPTLC2 p.(Arg183Trp) mutant. At 10-mM alanine, also a significant amount of 1-deoxySL was formed in SPTLC2wt cells, but 


\section{A}
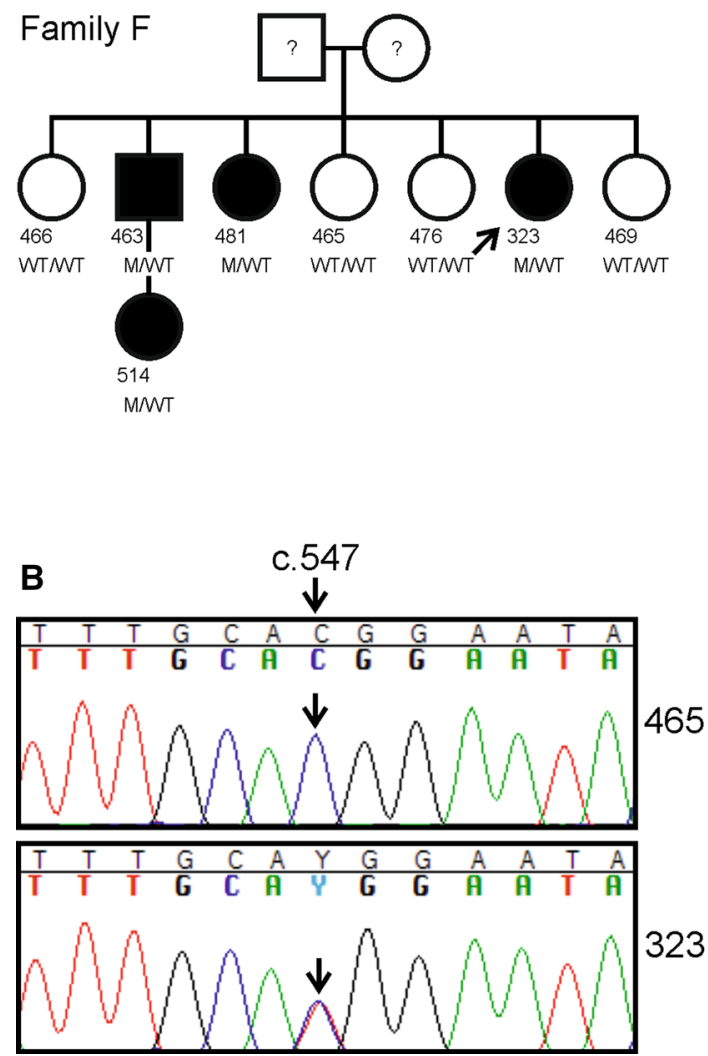

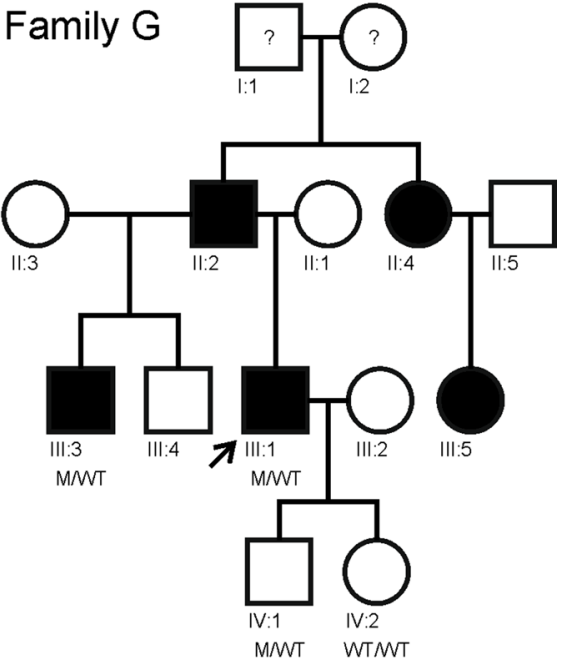

C

H. sapiens CSGTNRAFGLY

M. musculus CSGTNRAFGLY

C. lupus CAGTNRAFGLY

G. gallus CTGDNQAFGLY

$X$ tropicalis CEGTNQAFGLY

D. rerio CSGTNEAFGLY
Fig. 1 a Pedigrees of the studied Finnish (family F) and German (family G) families. The presence (M/WT) or absence (WT/WT) of the heterozygous SPTLC2 c.547C $>\mathrm{T}$ (p.(Arg183Trp)) variant is indicated. All carriers of the variant had symptoms or findings consistent with neuropathy (filled symbols), with the exception of the index patient's son in family G (IV:1), who did not yet show any symptoms at age 26. Individuals with no genotype indicated were not

levels were fourfold higher in SPTLC2 p.(Arg183Trp) cells. In contrast, at $10-\mathrm{mM}$ serine, canonical SPT activity was significantly increased in the SPTLC2 p.(Arg183Trp)-expressing cells (Fig. 3a), whereas 1-deoxySL formation was almost completely suppressed (Fig. 3b). Interestingly, no 1-deoxySO was formed at standard condition ( $1 \mathrm{mM} \mathrm{Ser}+2 \mathrm{mM}$ Ala), whereas significant amounts of 1-deoxySO were found in the $10 \mathrm{mM}$ Ala-stimulated cells. In the presence of SPT inhibitor myriocin, no isotope-labeled sphingoid bases were formed (data not shown).

\section{Serum Sphingolipid Measurements}

Serum samples were assayed for the canonical SPT products [sphinganine (SA) and sphingosine (SO)] and for the neurotoxic metabolites (1-deoxySA and 1-deoxySO).

In family $\mathrm{F}$, serum samples were obtained from four patients and two healthy family members. The average levels of SO were $60 \mu \mathrm{M}$ in patients and $61 \mu \mathrm{M}$ in controls, and average levels of SA were $3.0 \mu \mathrm{M}$ in patients and $3.2 \mu \mathrm{M}$ in available for closer study, and no information was available for individuals marked with question mark. Index patients are marked by arrows. b The variant was confirmed by Sanger sequencing. Representative chromatograms are shown for individuals 465 (wild type) and 323 (variant carrier) of family F. c Computational alignment of protein primary sequences showed that the p.Arg183 residue (arrow) is conserved in mammals

controls (Fig. 4a). The average serum levels of 1-deoxySO were $0.14 \mu \mathrm{M}$ and of 1-deoxySA $0.055 \mu \mathrm{M}$ in controls. Three patients $(323,463$, and 481$)$ had about fourfold increased levels, ranging between $0.46 \mu \mathrm{M}$ and $0.55 \mu \mathrm{M}$ for 1-deox ySO and between $0.21 \mu \mathrm{M}$ and $0.23 \mu \mathrm{M}$ for 1-deoxySA. One patient (514) had about twofold elevations, $0.20 \mu \mathrm{M}$ for 1-deoxySO and $0.12 \mu \mathrm{M}$ for 1-deoxySA (Fig. 4b).

In family $G$, serum samples were obtained from the index patient (III:1) and his son (IV:1). For control, serum from a healthy volunteer was used. The average levels of SO were $57 \mu \mathrm{M}$ in index patient, $50 \mu \mathrm{M}$ for his son, and $46 \mu \mathrm{M}$ in control, and the average levels of SA were $1.8 \mu \mathrm{M}$ in index patient, $2.1 \mu \mathrm{M}$ in his son, and $1.6 \mu \mathrm{M}$ in control (Fig. 4c). The average level of 1-deoxySO and 1-deoxySA in control was 0.05 and $0.03 \mu \mathrm{M}$, respectively. Index patient had 10-fold increase in the 1-deoxySO $(0.5 \mu \mathrm{M})$ and threefold increase in 1-deoxySA levels $(0.1 \mu \mathrm{M})$, and his son had threefold increase in 1-deoxySO $(0.015 \mu \mathrm{M})$ and 1.6-fold increase in 1-deoxySA level $(0.05 \mu \mathrm{M})$ compared to control (Fig. 4d). 


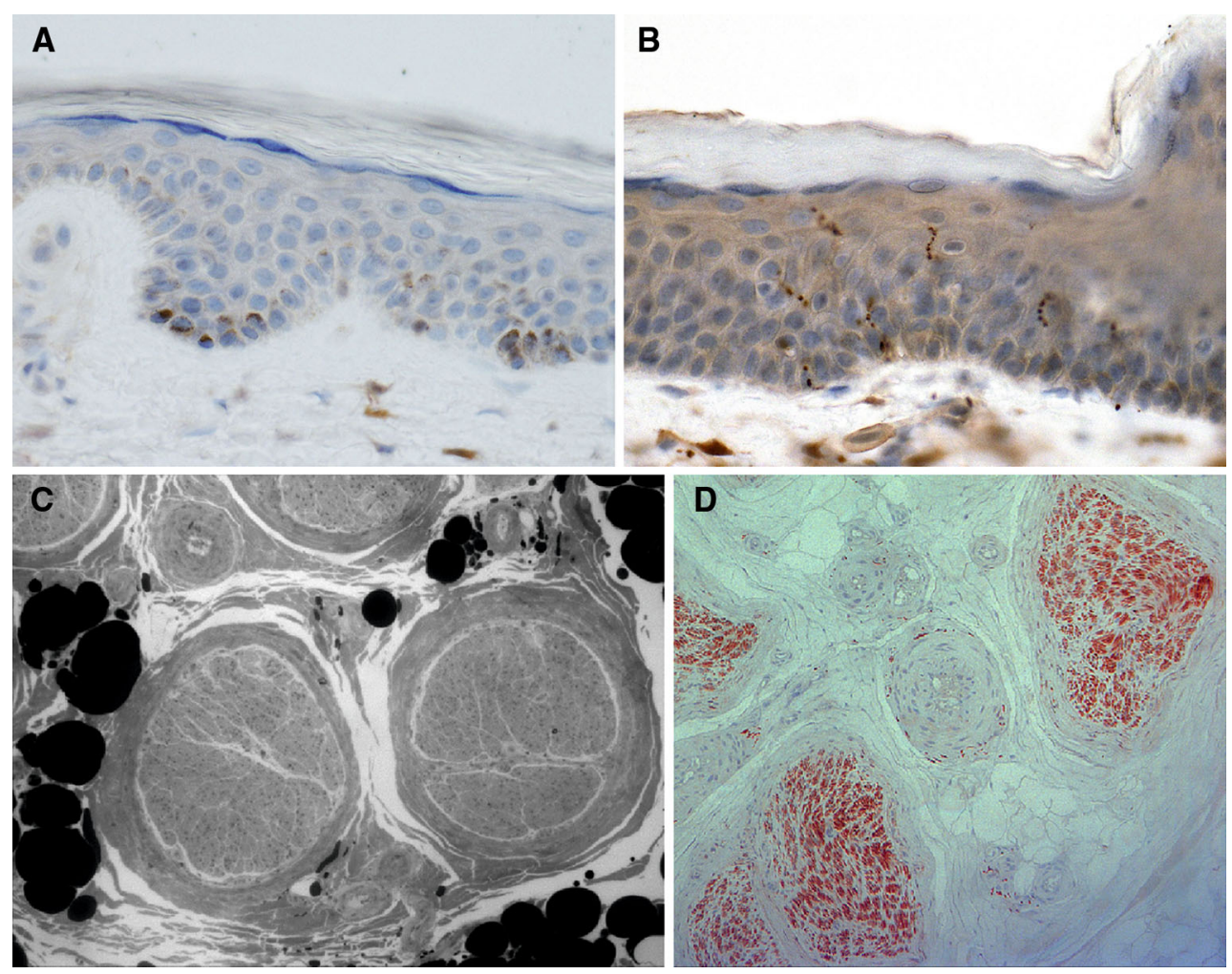

Fig. 2 a Patient (family F: 323 ) biopsy $10 \mathrm{~cm}$ above the lateral malleolus. PGP9.5 staining reveals no positive intraepidermal small nerve fibers. b Control skin biopsy from a neurologically intact (anonymous autopsy) patient from the same site showing seven intact intraepidermal small nerve fibers seen as undulating rows of pearls. PGP9.5 immunohistochemistry, $10-\mu \mathrm{m}$-thick paraffin sections, original magnification $\times 200(\mathbf{a}, \mathbf{b})$. c Sural nerve biopsy from patient III: 1 in family G, semithin transverse section, Toluidin-blue staining (black and white photo; magn. $\times 200$ ). Nerve fascicles without myelinating nerve fibers, only one myelinated fiber can be spotted in the right fascicle (myelin sheet is colored black). $\mathbf{d}$ Sural nerve biopsy from the same individual, transverse section $(5 \mu \mathrm{m}, \times 100)$, paraffin embedding, PGP 9.5 immunostaining. The number of endoneural unmyelinated fibers appears to be preserved
Table 2 Disease-associated haplotypes were determined in both families by measurement of STS marker sizes on both sides of SPTLC2 on chromosome $14 \mathrm{q} 24.3$

\begin{tabular}{|c|c|c|c|c|c|c|c|c|c|c|c|c|c|}
\hline \multirow{3}{*}{$\begin{array}{l}\text { Marker } \\
\text { AFM158XB4 }\end{array}$} & \multirow{3}{*}{$\begin{array}{l}\text { Distance from } \\
\text { variant } \\
-522 \mathrm{~kb}\end{array}$} & \multicolumn{8}{|c|}{ Family F } & \multicolumn{4}{|c|}{ Family G } \\
\hline & & \multicolumn{2}{|c|}{323} & \multicolumn{2}{|c|}{481} & \multicolumn{2}{|c|}{463} & \multicolumn{2}{|c|}{514} & \multicolumn{2}{|c|}{ III:1 } & \multicolumn{2}{|c|}{ IV:1 } \\
\hline & & 1 & 2 & 1 & 2 & 1 & 3 & 1 & 1 & 4 & 3 & 4 & 5 \\
\hline c. 547 & 0 & $\mathbf{T}$ & $\mathrm{C}$ & $\mathbf{T}$ & $\mathrm{C}$ & $\mathbf{T}$ & $\mathrm{C}$ & $\mathbf{T}$ & $\mathrm{C}$ & $\mathbf{T}$ & $\mathrm{C}$ & $\mathbf{T}$ & $\mathrm{C}$ \\
\hline D14S59 & $29 \mathrm{~kb}$ & 1 & 2 & 1 & 2 & 1 & 1 & 1 & 3 & 3 & 4 & 3 & 4 \\
\hline D14S109E & $175 \mathrm{~kb}$ & 1 & 2 & 1 & 2 & 1 & 2 & 1 & 2 & 3 & 4 & 3 & 5 \\
\hline AFM214XF8 & $336 \mathrm{~kb}$ & 1 & 2 & 1 & 2 & 1 & 1 & 1 & 3 & 4 & 1 & 4 & 4 \\
\hline
\end{tabular}

For each marker, the different sizes are numbered. The haplotype associating with the c.547C $>\mathrm{T}$ variant is highlighted in bold. Families F and G do not share a common disease haplotype, suggesting that the variant has emerged on separate occasions in the two families

\section{Discussion}

Here, we report a new disease-causing SPTLC2 variant p.(Arg183Trp) that elevates 1-deoxySL levels. Our data provide further insight into the clinical picture and associated biochemical abnormalities of HSAN1C disease.

The clinical picture in both the Finnish and the German family was a mild, late-onset axonopathy. Both index patients (family F, 323 and family G, III:1) reported first symptom in their mid-50s. The symptoms were initially sensory with later development of motor impairment and without autonomic involvement. In family $\mathrm{F}$, also individuals 463 and 481 carried the same SPTLC2 variant and reported similar symptoms. Patient 463 had not undergone neurophysiologic testing, and therefore, the presence of a peripheral neuropathy behind his numbness, clumsiness, and chronic foot infection could not be confirmed. The symptoms reported by patient 481 were similar to the index 


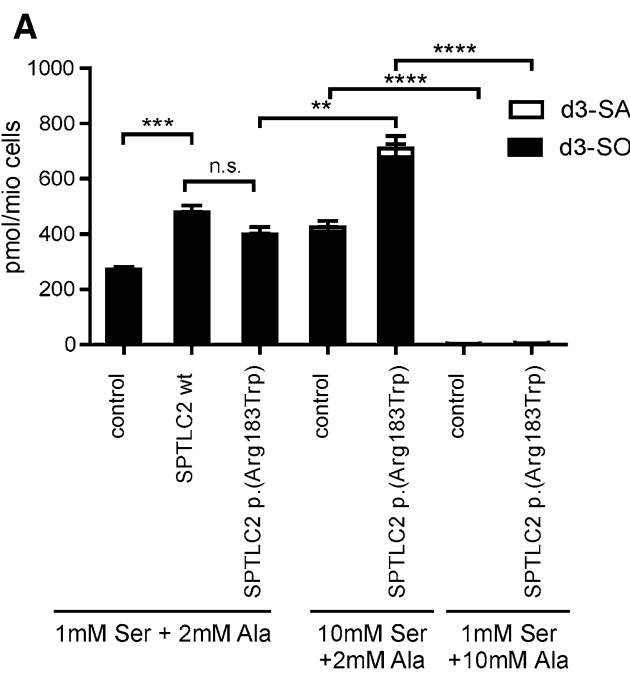

Fig. 3 SPT activity was measured in HEK293 cells transfected with the empty vector (control), wildtype SPTLC2 (SPTLC2wt) or the mutant [SPTLC2 p.(Arg183Trp)]. Cells were grown in the presence of isotope-labeled $\left(\mathrm{d}_{3},{ }^{15} \mathrm{~N}\right)$ L-serine $(1 \mathrm{mM}$ or $10 \mathrm{mM})$ and $\left(\mathrm{d}_{4}\right)$ alanine $(2 \mathrm{mM}$ or $10 \mathrm{mM}$ ) for $24 \mathrm{~h}$. a Levels of de novo formed sphinganine

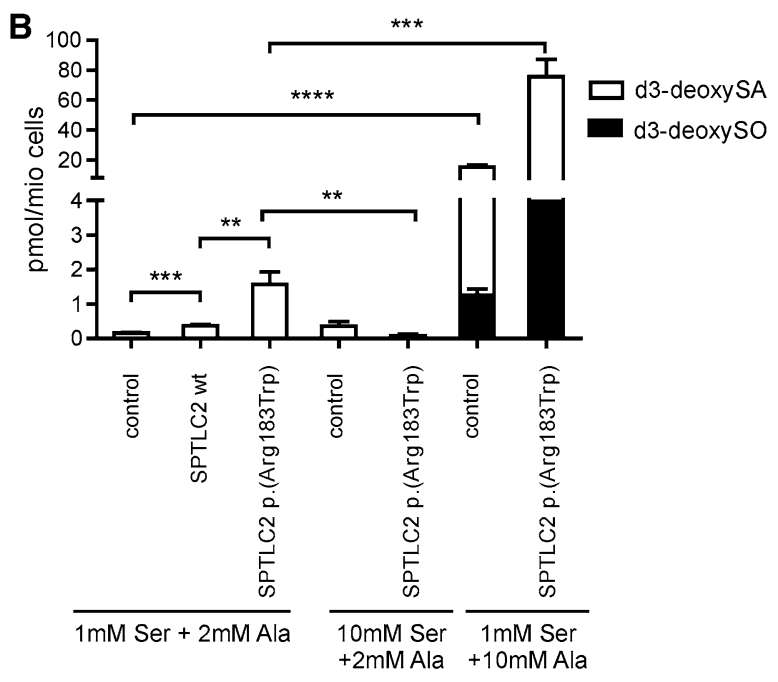

$\left(\mathrm{d}_{3}-\mathrm{SA}\right)$ and sphingosine $\left(\mathrm{d}_{3}-\mathrm{SO}\right)$. b Levels of de novo formed isotope-labeled 1-deoxy-sphinganine $\left(\mathrm{d}_{3}\right.$-deoxySA) and 1-deoxy-sphingosine $\left(\mathrm{d}_{3}\right.$-deoxySO). Data are shown as means with standard deviation. (n.s. not significant; $* p<0.05 ; \quad * * p<0.01$; $* * * p<0.001 ; * * * * p<0.0001)$
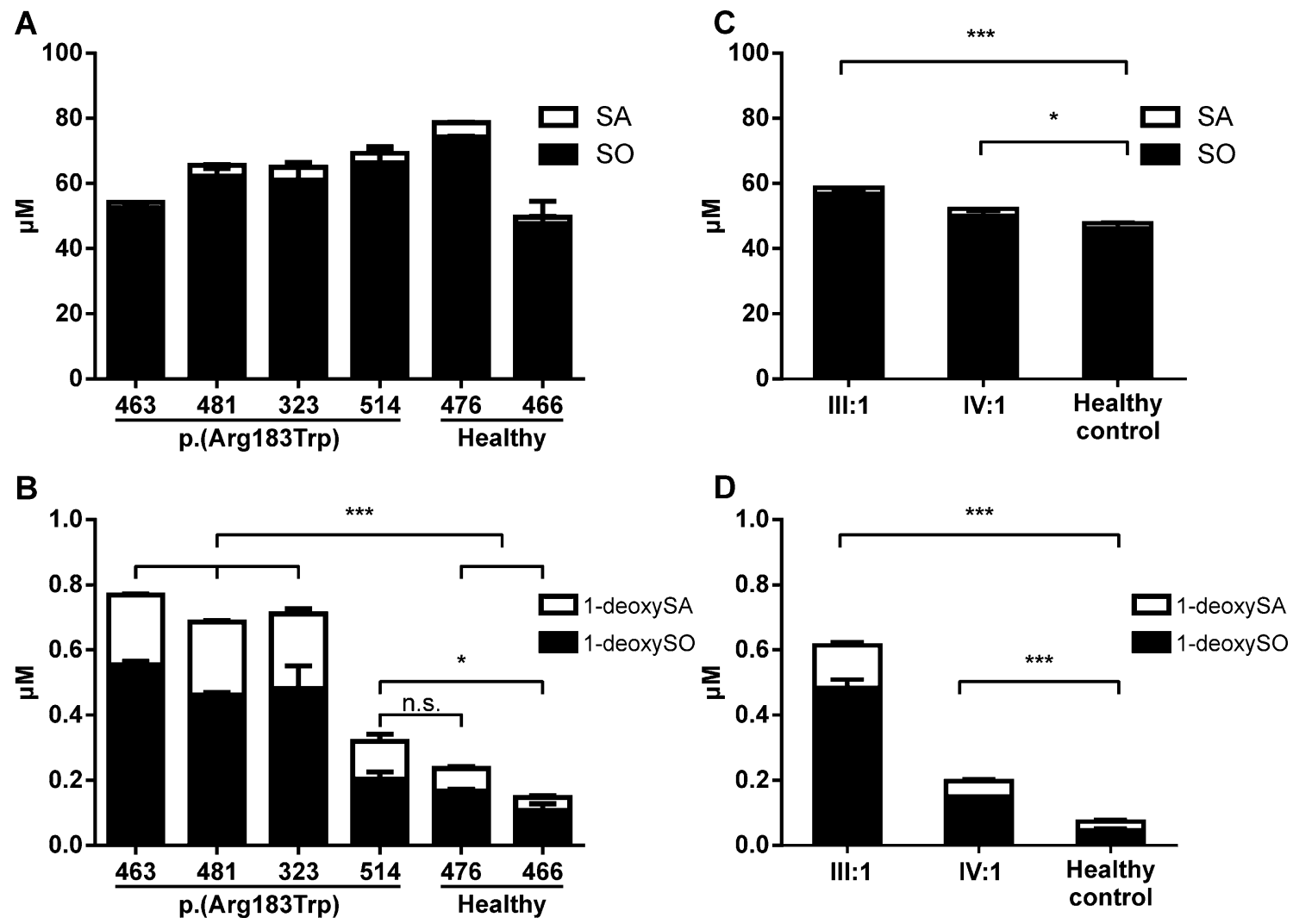

Fig. 4 Levels of sphinganine (SA), sphingosine (SO), 1-deoxysphinganine (1-deoxySA) and 1-deoxysphingosine (1-deoxySO) in serum of patients and controls. a For family $\mathrm{F}$ the levels for SA and SO were not different in comparison to unaffected family members. b 1-deoxySA and 1-deoxySO levels were significantly elevated in patients 463, 481 and 323 compared to unaffected family members (476 and 466). Patient 514 showed by trend higher 1-deoxySA and
1-deoxySO levels but differences were not significant in comparison to 476. c For family G levels of SA and SO were slightly elevated compared to non-related control plasma. d 1-deoxySA and 1-deox ySO levels were significantly higher in patients compared to control. All data are shown as means with standard deviation (n.s. not significant; $* p<0.05 ; * * p<0.01 ; * * * p<0.001)$ 
patient's, and her ENMG also supported sensorimotor axonal neuropathy. Individual 514 of family $\mathrm{F}$ had only reached the age of 50, which may explain why she had only minor symptoms and normal ENMG. The late-onset nature of the disease was further illustrated by individual IV:1 of family $\mathrm{G}$ being asymptomatic at age 26 . Overall, the moderate disease severity of our patients resembles the previously described patients with SPTLC2 p.(Gly382Val), p.(Val359Met) (Rotthier et al. 2010), and p.(Ser384Phe) (Ernst et al. 2015). More severe phenotypes were caused by the variants p.(Ala182Pro) (Murphy et al. 2013) and p.(Ile504Phe) (Rotthier et al. 2010).

Nerve biopsy obtained from the index patient in family $\mathrm{G}$ showed severe loss of myelinated axons, in line with previous findings in genetically confirmed HSAN1A patients (Lindahl et al. 2006; Houlden et al. 2006). The number of non-myelinated axons in the sural nerve appeared to be relatively preserved. However, a skin biopsy was not obtained from this patient, and thus, the presence of distal small fiber degeneration could not be assessed. The skin biopsy from the index patient in family F showed complete lack of intraepidermal nerve fibers, and her QST was consistent with small fiber impairment. Also, the mildly affected individual 514 had decreased cold sensation on QST and decreased small fiber density on biopsy, while her ENMG was normal. These findings suggest that distal small fibers that are undetectable on ENMG may degenerate before larger fibers. Thus, a small fiber neuropathy may be the first clinical presentation in a patient with SPTLC2 p.(Arg183Trp). In accordance, skin biopsy with PGP9.5 immunostaining was recently suggested as the best biomarker for HSAN1A disease (Fridman et al. 2015). Our results demonstrate that the neuropathy related to SPTLC2 p.(Arg183Trp) involves both small and large fiber types, with distal small fiber degeneration in the early stage of the disease.

The type 2 diabetes of patient 481 in family F and III:1 in family $G$ are important to note, since diabetes is a prevalent cause of neuropathy and also causes elevation of 1-deoxySL levels (Othman et al. 2012, 2015a, b). Moreover, 1-deoxySA has been shown to be cytotoxic for insulin-producing cells (Zuellig et al. 2014), suggesting that 1-deoxySA could even be an etiologic or diseasemodifying factor in diabetes. In both of our patients, the diabetes was mild or subclinical, which makes it unlikely to be the cause of their neuropathy. However, diabetes may be a contributory factor to the final clinical outcome. The other patients studied here did not have diabetes, which shows that it is not universal in HSAN1C. Nevertheless, given the potential toxicity of 1-deoxySA to insulin-producing cells, monitoring of plasma glucose and $\mathrm{HbA}_{1 \mathrm{C}}$ is clearly advisable in HSAN1C patients.
The overexpression of SPTLC2 p.(Arg183Trp) in HEK cells led to a level of 1-deoxySL production that was significantly higher than in cells overexpressing the wild-type SPTLC2. This abnormal SPT activity correlated with 1-deoxySL accumulation in patient serum, similar to previously described $S P T L C 1$ and $S P T L C 2$ variants (Rotthier et al. 2010; Penno et al. 2010; Garofalo et al. 2011). The degree of 1-deoxySL elevation shows correlation with the severity of the phenotype (Laura et al. 2012a, b). For instance, SPTLC2 p.(Ala182Pro) patients, who had relatively severe childhoodonset disease, had 1-deoxySO levels of up to $1.0 \mu \mathrm{M}$ (Murphy et al. 2013), approximately twofold compared to our p.(Arg183Trp) patients with disease-onset late in life.

In addition to the disease-causing variant itself, other genetic, environmental, and dietary factors may also influence clinical outcome in HSAN1C. Different blood 1-deoxySL levels have been seen among patients with the same disease variant and even within the same family. Within the group of SPTLC1 p.(Cys133Trp) carriers, we observed an up to fivefold difference in 1-deoxySL levels with the highest levels being recorded in the most severely affected patient (Penno et al. 2010). In family F, patient 514 had only modest 1 -deoxySL elevation compared to her affected family members. Her clinical picture also appeared mild, although she was younger than the other family members, and thus, we cannot exclude that the disease will progress similar to her relatives. In family G, the index patient had markedly elevated 1-deoxySL levels, while his pre-symptomatic son only showed mild elevation. Therefore, identifying environmental modifiers, e.g., amino acids especially serine and alanine from diet, triglycerides or exercise, which may mitigate 1-deoxySL accumulation, could have important implications for patient treatment and counseling.

HSAN1 is important to diagnose since it may be amenable to rational treatment. Increasing L-serine through dietary supplementation lowered 1-deoxySL levels and improved the neuropathy of transgenic mice carrying Sptlc1 p.(Cys133Trp). A 10-week pilot trial with 14 human SPTLC1 p.(Cys133Tyr) carriers showed lowering of serum 1-deoxySL levels upon L-serine supplementation with no overt toxicity (Garofalo et al. 2011). However, L-serine supplementation has not been systematically tested in HSAN1C patients so far. Also for the SPTLC2 p.(Arg183Trp) mutant, 1-deoxySL formation was largely suppressed in the presence of $10 \mathrm{mM} \mathrm{L}$-serine, whereas 1-deoxySL formation was significantly increased at $10 \mathrm{mM}$ L-alanine (Fig. 3b). Therefore, L-serine supplementation should be considered as a potential therapeutic approach also for the $S P T L C 2$ p. $(\operatorname{Arg} 183 \operatorname{Trp})$ variant.

With this report, disease-causing variants in SPTLC2 have been found in several European countries, and future 
coordinated efforts may allow the possibility of treating these patients to be assessed.

Our study has expanded the clinical and genetic spectrum of HSAN1C. We have shown that the p.(Arg183Trp) variant in SPTLC2 leads to late-onset neuropathy, which is predominantly sensory but with later motor involvement. Distal small fibers appear to be affected prior to large myelinated fibers. Similar to other genetic causes of HSAN1A and HSAN1C, SPTLC2 p.(Arg183Trp) is associated with significantly elevated 1-deoxySL blood levels. Therefore, testing of this gene or an analysis of the blood sphingoid bases is recommended in similar phenotypes, particularly due to the future possibility for a specific treatment.

Acknowledgments In memoriam to B.R. a dear colleague and friend who unexpectedly passed away too premature. We thank Riitta Lehtinen for technical assistance. The authors wish to thank the following funding sources for support: Hospital District of Helsinki and Uusimaa (for M.A. and E.Y.), Sigrid Jusélius Foundation (for H.T.), University of Helsinki (for H.T.), the Academy of Finland (for H.T. and E.Y.), The 7th Framework Program of the European Commission ("RESOLVE", Project Number 305707) for S.S. Furthermore, T.H. and S.S are grateful to the Hurka Foundation, the Novartis Foundation, and the Rare Disease Initiative Zurich ("radiz", Clinical Research Priority Program for Rare Diseases, University of Zurich).

\section{Compliance with Ethical Standards}

Conflict of interest The authors declare no conflict of interest.

\section{References}

Adzhubei, I. A., Schmidt, S., Peshkin, L., Ramensky, V. E., Gerasimova, A., Bork, P., et al. (2010). A method and server for predicting damaging missense mutations. Nature Methods, 7 , 248-249. doi:10.1038/nmeth0410-248.

Bejaoui, K., Wu, C., Scheffler, M. D., Haan, G., Ashby, P., Wu, L., et al. (2001). SPTLC1 is mutated in hereditary sensory neuropathy, type 1. Nature Genetics, 27, 261-262. doi:10.1038/85817.

Dawkins, J. L., Hulme, D. J., Brahmbhatt, S. B., Auer-Grumbach, M., \& Nicholson, G. A. (2001). Mutations in SPTLC1, encoding serine palmitoyltransferase, long chain base subunit-1, cause hereditary sensory neuropathy type I. Nature Genetics, 27, 309-312. doi:10.1038/85879.

Ernst, D., Murphy, S. M., Sathiyanadan, K., Wei, Y., Othman, A., Laura, M., et al. (2015). Novel HSAN1 mutation in serine palmitoyltransferase resides at a putative phosphorylation site that is involved in regulating substrate specificity. NeuroMolecular Medicine, 17, 47-57. doi:10.1007/s12017-014-8339-1.

Fridman, V., Oaklander, A. L., David, W. S., Johnson, E. A., Pan, J., Novak, P., et al. (2015). Natural history and biomarkers in hereditary sensory neuropathy type 1. Muscle and Nerve, 51, 489-495. doi:10.1002/mus.24336.

Garofalo, K., Penno, A., Schmidt, B. P., Lee, H. J., Frosch, M. P., von Eckardstein, A., et al. (2011). Oral L-serine supplementation reduces production of neurotoxic deoxysphingolipids in mice and humans with hereditary sensory autonomic neuropathy type
1. Journal of Clinical Investigation, 121, 4735-4745. doi:10. 1172/JCI57549.

Guelly, C., Zhu, P. P., Leonardis, L., Papic, L., Zidar, J., Schabhuttl, M., et al. (2011). Targeted high-throughput sequencing identifies mutations in atlastin-1 as a cause of hereditary sensory neuropathy type I. American Journal of Human Genetics, 88, 99-105. doi:10.1016/j.ajhg.2010.12.003.

Hanada, K. (2003). Serine palmitoyltransferase, a key enzyme of sphingolipid metabolism. Biochimica et Biophysica Acta, 1632, $16-30$.

Houlden, H., Blake, J., \& Reilly, M. M. (2004). Hereditary sensory neuropathies. Current Opinion in Neurology, 17, 569-577.

Houlden, H., King, R., Blake, J., Groves, M., Love, S., Woodward, C., et al. (2006). Clinical, pathological and genetic characterization of hereditary sensory and autonomic neuropathy type 1 (HSAN I). Brain, 129, 411-425.

Kircher, M., Witten, D. M., Jain, P., O'Roak, B. J., Cooper, G. M., \& Shendure, J. (2014). A general framework for estimating the relative pathogenicity of human genetic variants. Nature Genetics, 46, 310-315. doi:10.1038/ng.2892.

Klein, C. J., Botuyan, M. V., Wu, Y., Ward, C. J., Nicholson, G. A., Hammans, S., et al. (2011). Mutations in DNMT1 cause hereditary sensory neuropathy with dementia and hearing loss. Nature Genetics, 43, 595-600. doi:10.1038/ng.830.

Kornak, U., Mademan, I., Schinke, M., Voigt, M., Krawitz, P., Hecht, J., et al. (2014). Sensory neuropathy with bone destruction due to a mutation in the membrane-shaping atlastin GTPase 3. Brain, 137, 683-692. doi:10.1093/brain/awt357.

Koskinen, M., Hietaharju, A., Kylaniemi, M., Peltola, J., Rantala, I., Udd, B., \& Haapasalo, H. (2005). A quantitative method for the assessment of intraepidermal nerve fibers in small-fiber neuropathy. Journal of Neurology, 252, 789-794. doi:10.1007/ s00415-005-0743-x.

Laura, M., Eichler, F., Hornemann, T., Murphy, S. M., Polke, J., Bull, K., et al. (2012a). Hereditary sensory and autonomic neuropathy type 1: correlation of severity and plasma atypical deoxysphyngoid bases. Journal of Neurology, Neurosurgery and Psychiatry, 83, e1. doi:10.1136/jnnp-2011-301993.16.

Laura, M., Murphy, S. M., Hornemann, T., Bode, H., Polke, J., Blake, J., et al. (2012b). Hereditary sensory neuropathy type 1: Correlation of severity and plasma atypical deoxy-sphyngoid base. Neuromuscular Disorders, 22, S18. doi:10.1016/S09608966(12)70050-0.

Lim, E. T., Wurtz, P., Havulinna, A. S., Palta, P., Tukiainen, T., Rehnstrom, K., et al. (2014). Distribution and medical impact of loss-of-function variants in the finnish founder population. PLoS Genetics, 10, e1004494. doi:10.1371/journal.pgen.1004494.

Lindahl, A. J., Lhatoo, S. D., Campbell, M. J., Nicholson, G., \& Love, S. (2006). Late-onset hereditary sensory neuropathy type I due to SPTLC1 mutation: Autopsy findings. Clinical Neurology and Neurosurgery, 108, 780-783.

Murphy, S. M., Ernst, D., Wei, Y., Laura, M., Liu, Y. T., Polke, J., et al. (2013). Hereditary sensory and autonomic neuropathy type 1 (HSANI) caused by a novel mutation in SPTLC2. Neurology, 80, 2106-2111. doi:10.1212/WNL.0b013e318295d789.

Othman, A., Bianchi, R., Alecu, I., Wei, Y., Porretta-Serapiglia, C., Lombardi, R., et al. (2015a). Lowering plasma 1-deoxysphingolipids improves neuropathy in diabetic rats. Diabetes, 64, 1035-1045. doi:10.2337/db14-1325.

Othman, A., Rutti, M. F., Ernst, D., Saely, C. H., Rein, P., Drexel, H., et al. (2012). Plasma deoxysphingolipids: A novel class of biomarkers for the metabolic syndrome? Diabetologia, 55, 421-431. doi:10.1007/s00125-011-2384-1.

Othman, A., Saely, C. H., Muendlein, A., Vonbank, A., Drexel, H., von Eckardstein, A., \& Hornemann, T. (2015b). Plasma 
1-deoxysphingolipids are predictive biomarkers for type 2 diabetes mellitus. BMJ Open Diabetes Research and Care, 3, e000073. doi:10.1136/bmjdrc-2014-000073.

Penno, A., Reilly, M. M., Houlden, H., Laura, M., Rentsch, K., Niederkofler, V., et al. (2010). Hereditary sensory neuropathy type 1 is caused by the accumulation of two neurotoxic sphingolipids. Journal of Biological Chemistry, 285, 11178-11187. doi:10.1074/jbc.M109.092973.

Rotthier, A., Auer-Grumbach, M., Janssens, K., Baets, J., Penno, A., Almeida-Souza, L., et al. (2010). Mutations in the SPTLC2 subunit of serine palmitoyltransferase cause hereditary sensory and autonomic neuropathy type I. American Journal of Human Genetics, 87, 513-522. doi:10.1016/j.ajhg.2010.09.010.

Verhoeven, K., De Jonghe, P., Coen, K., Verpoorten, N., AuerGrumbach, M., Kwon, J. M., et al. (2003). Mutations in the small GTP-ase late endosomal protein RAB7 cause Charcot-Marie-
Tooth type 2B neuropathy. American Journal of Human Genetics, 72, 722-727. doi:10.1086/367847.

Wang, K., Li, M., \& Hakonarson, H. (2010). ANNOVAR: Functional annotation of genetic variants from high-throughput sequencing data. Nucleic Acids Research, 38, e164. doi:10.1093/nar/gkq603.

Ylikallio, E., Johari, M., Konovalova, S., Moilanen, J. S., KiuruEnari, S., Auranen, M., et al. (2014). Targeted next-generation sequencing reveals further genetic heterogeneity in axonal Charcot-Marie-Tooth neuropathy and a mutation in HSPB1. European Journal of Human Genetics, 22, 522-527. doi:10. 1038/ejhg.2013.190.

Zuellig, R. A., Hornemann, T., Othman, A., Hehl, A. B., Bode, H., Guntert, T., et al. (2014). Deoxysphingolipids, novel biomarkers for type 2 diabetes, are cytotoxic for insulin-producing cells. Diabetes, 63, 1326-1339. doi:10.2337/db13-1042. 